\title{
EDITORIAL
}

\section{Is a meta-analysis of a few low-level publications helpful in guiding surgical strategies?}

\author{
Bernhard Meyer, MD \\ Department of Neurosurgery, Klinikum rechts der Isar, Technical University of Munich, Germany
}

$\mathrm{T}$ o begin this editorial by answering the above question, I have to say, it is not. The article by Govindarajan et al. ${ }^{1}$ serves one purpose; it reinforces the fact that there is still a lack of knowledge regarding which surgical approach is best to treat ankylosing spondylitis (AS) fractures of the subaxial cervical spine. It summarizes in a quantitative analysis only 7 fairly recent publications with a very low level of evidence and not enough relevant data to draw even moderately certain conclusions.

Therefore, I am unhappy to see the sentence "While reports demonstrated lower degrees of neurological improvement in anterior approaches, they may benefit patients with less-severe injuries if lower complication rates are desired" in the Conclusions of the article's abstract. The rate of neurological improvement is not the right primary outcome parameter, and above that, is hard to consolidate in a retrospective series, apart from the fact that only a fraction of the patients had a neurological deficit.

What is most likely true, though not proven, is that combined approaches increase complication rates, both surgical complications and, even more important, systemic ones. A posterior or anterior approach alone probably makes no difference in complication rates, as pointed out in an earlier review. ${ }^{2}$ The feasibility of an anterior-only approach is something most peers would have doubts about, and I would be very careful to deduce this from a single series. ${ }^{3}$ The only thing to be learned from this study is that even the authors themselves did not trust their anterior-only construct because, in addition to the surgery, they used external immobilization of the cervical spine and kept the patients immobilized. This is a counterintuitive concept for me as these frail patients need the contrary. This cohort is a typical example for the benefit of geriatric surgery. These procedures are done to have patients up and moving as soon as possible in case of a neurological deficit. There is no place for bed rest or external cervical or cervicothoracic immobilization, given the notorious pulmonary restrictions most of these patients have, and also no place for revision surgeries. An anterior plate alone does not have the biomechanical strength to withstand the large forces of a longer lever arm of a stiff spine with mostly very poor bone quality.

Accepting that there is no proof or even halfway solid data to substantiate my point, I nevertheless postulate the following: the best way to treat AS fractures of the subaxial cervical spine is a fairly long (at least 2 levels above and below) posterior-only construct, preferentially with biomechanically superior pedicle screws ${ }^{4}$ which should be placed with image guidance to avoid any surprises. ${ }^{5} \mathrm{An}$ additional anterior approach can almost always be avoided. I admit this is spoken ex cathedra and is only derived from 30 years of experience and a huge caseload in a major center. And I admit, further, that I may be wrong and would like to see my opinion corroborated or falsified by a proper study. This should be a prospective observational multicenter study in the sense of a registry with complete and accurate data sets. ${ }^{6}$

https://thejns.org/doi/abs/10.3171/2021.7.FOCUS21432

\section{References}

1. Govindarajan V, Bryant JP, Perez-Roman RJ, Wang MY. The role of an anterior approach in the treatment of ankylosing spondylitis-associated cervical fractures: a systematic review and meta-analysis. Neurosurg Focus. 2021;51(4):E9.

2. Longo UG, Loppini M, Petrillo S, Berton A, Maffulli N, Denaro V. Management of cervical fractures in ankylosing spondylitis: anterior, posterior or combined approach? $\mathrm{Br}$ Med Bull. 2015;115(1):57-66.

3. Guo Q, Cui Y, Wang L, Lu X, Ni B. Single anterior approach for cervical spine fractures at C5-T1 complicating ankylosing spondylitis. Clin Neurol Neurosurg. 2016;147:1-5.

4. Schmidt R, Wilke HJ, Claes L, Puhl W, Richter M. Pedicle screws enhance primary stability in multilevel cervical corpectomies: biomechanical in vitro comparison of different 
implants including constrained and nonconstrained posterior instumentations. Spine (Phila Pa 1976). 2003;28(16):18211828.

5. Rienmüller A, Buchmann N, Kirschke JS, Meyer EL, Gempt J, Lehmberg J, et al. Accuracy of CT-navigated pedicle screw positioning in the cervical and upper thoracic region with and without prior anterior surgery and ventral plating. Bone Joint J. 2017;99-B(10):1373-1380.

6. Meyer B, Shiban E, Albers L, Krieg SM. Completeness and accuracy of data in spine registries: an independent auditbased study. Eur Spine J. 2020;29(6):1453-1461.

\section{Disclosures}

The author reports no conflict of interest.

\section{Correspondence}

Bernhard Meyer: bernhard.meyer@tum.de.

\section{INCLUDE WHEN CITING}

DOI: 10.3171/2021.7.FOCUS21432. 